\title{
Technical Notes:
}

\section{A Rumen Cannula for Small Ruminants}

\author{
WILLIAM H. MILLER AND MICHAEL MALTBY
}

\begin{abstract}
A ridged rumen cannula made from polyvinyl chloride pipe fittings and plexi-glass at a material's cost of $\mathbf{\$ 2 . 5 0}$, is ideally suited for use on small ruminants. Its advantages over other rumen cannula designs include its simple construction, maintenance, ease of sampling, and immediate availability for use following surgical installation. A threaded outer adjustable washer provides a means of lightly tightening the cannula to the body wall thus preventing leakage and dislodgment of the cannula. The cannula can be adapted for various small ruminants by varying the size of the pipe fittings used to construct the cannula.
\end{abstract}

Recent research in range nutrition has placed an increased emphasis on evaluation of the digestible components of grazing animal diets. In vitro digestion techniques similar to those developed by Tilley and Terry (1963) provide the best means of evaluating the digestiblity of the diet. All of these in vitro digestion experiments require relatively large amounts of rumen fluid. Since both the quantity and quality of rumen fluid obtained by stomach tubing small ruminants (sheep, goats, deer) is marginal, an alternative means of collecting the rumen fluid is preferable.

This paper describes the construction and advantages of an inexpensive rumen cannula for use in small ruminants to facilitate the collection of rumen liquor for in vitro digestion trials.

\section{Materials and Methods}

The cannula, constructed from polyvinyl choloride (pvc) fittings and plexi-glass, uses a gastro-intestinal design similar to Hecker (1974). The materials required to construct a cannula with an outside diameter of $48 \mathrm{~mm}$ include a: $19 \mathrm{~mm}(3 / 4 \mathrm{in}$.) threaded pvc coupling, with a $19 \mathrm{~mm}(3 / 4 \mathrm{in}$.) threaded cap, a $75 \mathrm{~mm}(3 \mathrm{in}$.) diam $\times 6 \mathrm{~mm}(1 / 4 \mathrm{in}$.) thick plexi-glass disk, a $63 \mathrm{~mm}(21 / 2 \mathrm{in}$. $)$ diam $\times$ $6 \mathrm{~mm}(1 / 4 \mathrm{in}$.) thick plexi-glass disk (Fig. 1A); pvc cleaner; and pvc glue. The fittings are all schedule $40 \mathrm{pvc}$. Sizes are standard nominal measurements with the total cost of materials less than $\$ 2.50$.

Assembly of the cannula begins by center drilling the larger plexi-glass disk to the outside diameter of the nonthreaded portion of the pipe fitting $(48 \mathrm{~mm})$. Once glued to the bottom of the pvc fitting, the larger disk becomes the interruminal flange. The smaller disk then is center drilled to the same outside diameter as the threaded portion of the pvc fitting $(26 \mathrm{~mm})$, and threaded with standard pipe threads. In this configuration the smaller disk becomes the outer securing washer. The completed cannula with cap weighs $86 \mathrm{~g}$ (Fig. 1B).

The cannula is implanted using a modification of the single stage technique described by Dougherty (1981). Once implanted the cannula is held in place by the threaded securing washer and cap (Fig. 2). Securing pressure can be adjusted by loosening or tightening the securing washer.

\section{Discussion}

This cannula is similar to the one described by Hecker (1974), but differs from the traditional rubber Jarretta type cannula described by Johnson (1966). The advantages of the present design include the use of nonirritating, light weight pvc fittings and plexiglass that enable easy construction and require low maintenance when implanted in rumen-fistulated animals. Some variation in barrel size (ranging from the $19 \mathrm{~mm}$ ( $3 / 4 \mathrm{in}$.) inside diameter used in

\footnotetext{
Authors are assistant professor and research assistant, Division of Agriculture, Arizona State University, Tempe 85287.

Manuscript accepted 16 December 1985.
}
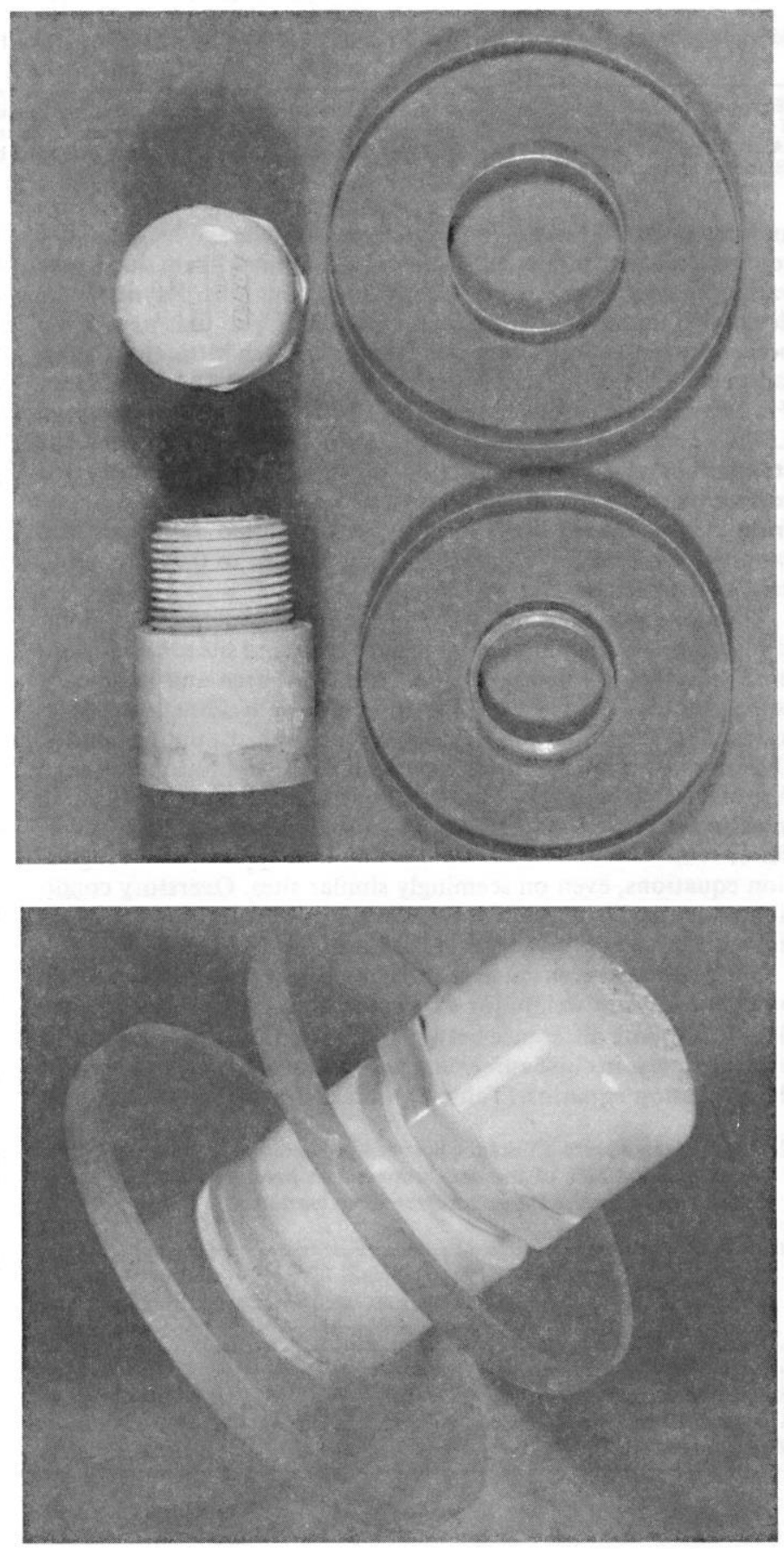

Fig. 1. Construction of rumen cannula (A) component parts (B) fully assembled cannula.

this paper to fittings with $50 \mathrm{~mm}$ ( 2 in.) inside diameter can occur by using different size standard fittings. Additionally, the combination of ridged barrel and internal flange coupled with the threaded 


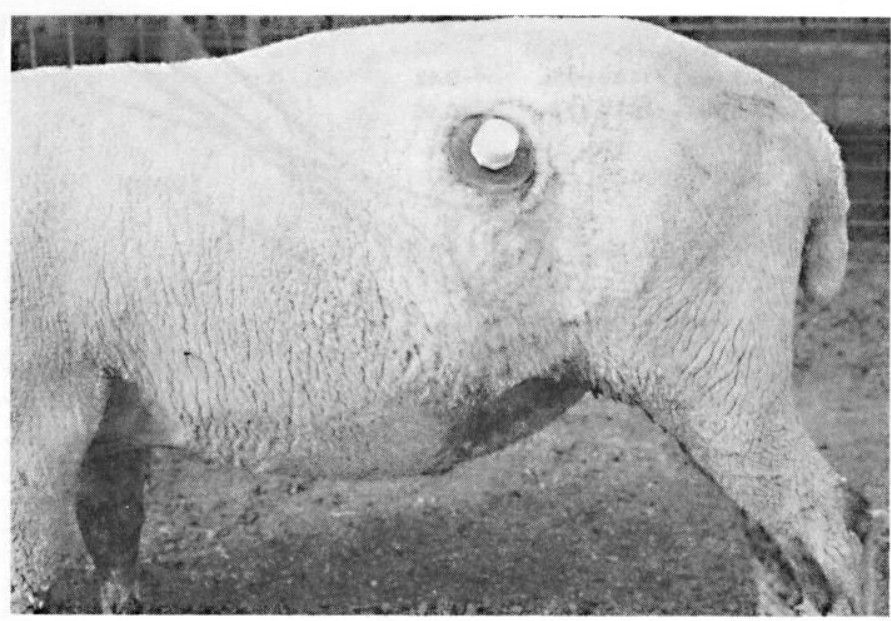

Fig. 2. Rumen cannula installed in a sheep.

outer securing washer reduce the dislodging problems associated with rubber cannulas.

An added advantage of this design is that by regulating the pressure of the threaded securing washer, allowance can be made for tissue swelling surrounding the barrel at the time of fistulation. Once the post surgical swelling has subsided, the outer securing washer can be adjusted to prevent leakage of rumen contents from around the cannula.
Collection of rumen fluid is easily performed from animals fistulated with this cannula. Samples can be collected by means of a hand operated suction pump or manual abdominal pressure to express rumen content through the fistula. In an average $45 \mathrm{~kg}$ sheep as much as $750 \mathrm{ml}$ of rumen contents, or sufficient rumen fluid for 60-70 individual in vitro digestions can be obtained daily.

A further advantage of this cannula is that sampling from the rumen can begin immediately after the initial surgery. Fistulation using a Jarrette cannula (Johnson 1960) requires approximately 2 to 3 weeks recovery before the cannula can be inserted in the rumen.

One disadvantage of this cannula, along with other small cannulas, is that the restricted size of the opening reduces the opportunity to accomplish in vivo micro-digestion studies on forages. This problem can be partially mediated by using the larger size fittings. A second disadvantage comes from the ridged design of the cannula. Should there be a need to remove the cannula for any reason, the internal flange is too large to pass through the tissue opening.

Both sheep and deer outfitted with these cannulas have been successfully maintained for periods in excess of 1 year with no complications. The low cost and ease of construction coupled with the dependability of the design make this type of cannula desirable for small ruminant nutrition studies.

\section{Literature Cited}

Dougherty, R.W. 1981. Experimental surgery in farm animals. Iowa State University Press, Ames.

Hecker, J.F. 1974. Experimental surgery on small ruminants. Butterworths and Co., London.

Johnson, R.R. 1966. Techniques and procedures for in vitro and in vivo rumen studies. J. Anim. Sci. 25:855-875.

Tilley, J.M.A., and R.A. Terry. 1963. A two-stage technique for the in vitro digestion of forage crops. J. Brit. Grassland Soc. 18:104-111. 